\title{
Revisión del conjunto de dinares almorávides de la Loma de la Buitrera (Jaén)
}

\author{
Ma Teresa Campos López *
}

\begin{abstract}
RESUMEN
Revisión de un conjunto de dinares almorávides depositados en el Museo Provincial de Jaén y traspasados del Instituto de Estudios Giennenses, hallado en la Loma de la Buitrera, cerca de Jimena.

Las piezas presentan una cronología que abarca desde el año 49 | H/ | 097d.0 al 533H/l I39d.C.

Responden a la tipología típica de las emisiones de este período aunque se documentan peculiaridades en algunas de ellas e, incluso, una pieza inédita acuñada en Badajoz.
\end{abstract}

PALABRAS CLAVE: Dinares, Almorávides, Ceca, Acuñación, Leyendas, Orla, Averso, Reverso

Hace algún tiempo iniciamos la revisión de los conjuntos numismáticos árabes del Museo Provincial de Jaén con el fin de clasificar el material inédito $y$, como en este caso, retomar y actualizar estudios anteriores.

Nos ocupamos en esta ocasión de un conjunto de dinares del período almorávide I, que llegaron a las dependencias de este Museo cuando se realizó el traspaso de los fondos del Instituto de Estudios Giennenses, en 1968, según los registros.

\begin{abstract}
This article presents the revision of a group of Almoravid dinars kept in the Museum of Jaen, donated by the "Instituto de Estudios Giennenses", and that were founded at the Loma de la Buitrera, near of the town of Jimena.

The coins' chronology goes from the year 49 । H/ I 097d.0 to $533 \mathrm{H} / \mathrm{I}$ I 39d.C.

They have the typical type of the emissions of this period but there are some peculiarities in a few of them and, also, there one piece unpublished minting in Badajoz.
\end{abstract}

KEY WORDS: Dinars, Almoravids, Mint, (to) mint, Inscription, Border, Obverse, Reverse

Apareció en la Loma de la Buitrera, localizada cerca de la localidad jiennense de Jimena, en una finca propiedad de D. José María Torres Hermoso.

un artículo de fecha anterior a dicho traspaso (PINERO JIMÉNEZ, MARTíNEZ ROMERO, 1955), queda reflejado que el total del conjunto constaba de 39 piezas, de las que 21 entraron a formar parte de los fondos del Instituto de Estudios Giennenses 2, aunque en la actualidad, en el Museo Provincial, sólo se conser-

\footnotetext{
* Universidad de Jaén

I Cuyos números de registro van del 3316 al 3334.

2 Cuyos números de inventario iban del I440 al I458.
} 
van 19, faltando, por tanto, dos piezas: un dinar de ceca Almería y fecha 524H/ I I 29 d.C y otro de ceca Murcia y fecha 503H/l I09 d.C 3 .

La mencionada publicación presenta un estudio bastante acertado de las piezas pero, sin embargo, no aparece referencia a ningún tipo de clasificación (como podría ser el Vives, que nosotros hemos incluido en nuestro estudio). Siendo el aspecto más interesante de dicho artículo el estudio de las distintas variaciones en las leyendas y utilizaciones de unas palabras en vez de otras en las leyendas. No obstante hemos detectado algunas incompatibilidades entre ciertas fechas y gobernantes.

\section{RESEÑA HISTÓRICA}

Los almorávides ( I 056- | | 46 d.C/448-54 | H) eran un movimiento surgido en el sur del Sahara, que había abrazado un Islam rigorista con un fuerte contenido militar en el que el Estado se identificaba con el ejército, siendo uno de sus principales pilares la práctica de la ŷihād o guerra santa.

El vacío político existente en el norte de África tras la caída del califato cordobés permitió a los Álmorávides la creación de un imperio que llegó a abarcar desde el actual Marruecos hasta Argelia Occidental en relativamente poco tiempo.

Mientras, en la península, la ocupación de Toledo por Alfonso VI ( 085 d.Cl 477H) dejó en evidencia la debilidad de los reinos de taifas. Éstas se vieron liberadas de la presión cristiana al pedir ayuda al sultán almorávide Yūsuf ibn Tāšsin para caer, pronto, bajo el dominio almorávide.

Pese a la anulación de los impuestos extracoránicos en un principio, los fracasos militares dieron lugar a que, para poder mantener la estructura estatal y fortificar el territorio, se vieran obligados a subir los impuestos, lo que ocasionó, junto con su actuación como casta elitista, movimientos de oposición.

Hacia I I 40d.C/ 534H llegan noticias de su derrota en el Magreb bajo los Almohades y, poco a poco, se irá reconociendo a éstos en vez de a los Almorávides.

\section{LA MONEDA}

Esta etapa se identifica con una nueva moneda de oro, el dinar, denominado como "morabetino" en las fuentes y crónicas castellanas. De insuperable calidad, llegará a ser la moneda más codiciada de todo el mundo medieval.

El dirham almorávide, que también se acuñó sobre todo bajo el llamado quirate ${ }^{4}$, es menos espectacular que el dinar. La aparición de la ceca en estas piezas es excepcional y algunos quirates tardíos aparecen con escritura nasjí (de tipo cursivo).

Al contrario que en época omeya, los almorávides hicieron frente al problema de la falta de moneda fraccionaria con la emisión de una serie de fracciones de quirate que eliminan la necesidad de recortar y alterar las piezas por parte de la población.

La moneda almorávide supone la vuelta a modelos "legales" con una red de cecas abundantes. Esta misma sujección a la legitimidad coránica hizo que casi todas las grandes poblaciones, que habían sido capitales en los Reinos de Taifas, acuñaran moneda bajo el nombre de los nuevos dominadores.

En lo que se refiere al volumen de acuñación es, sin duda, de 'Alī ibn Yūsuf (500-37H/ I I 06- I | 43d.C) del que se conocen un mayor número de piezas, de distintos metales, tipos y cecas.

\footnotetext{
3 Y que en dicho artículo (PINERO JIMÉNEZ, MARTíNEZ ROMERO, 1955) se corresponden con las piezas con los números 6 y 10.

4 Cuyo diámetro varía entre 10 y $14 \mathrm{~cm}$ y su peso es de I gramo, frente a las medidas de un dirham que se encuentran entre 20 y $25 \mathrm{~cm}$ de módulo y entre 2 '5 y 3 gramos de peso.
} 


\section{Estructura de las piezas}

La distribución de las leyendas en los dinares almorávides es la misma que en época califal: una leyenda central con otra inscripción en la orla, separadas por una línea continua circular (como grafila interna) y bordeando la moneda dos líneas circulares muy próximas (grafila externa).

A continuación presentamos las transcripciones de las leyendas que aparecen en las piezas de este periodo.

\section{Anverso}

Leyenda central anverso:

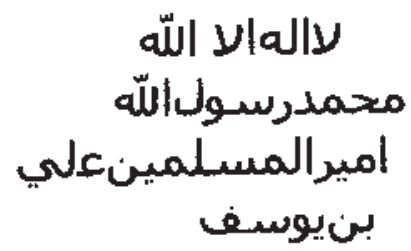

No (hay) dios sino Allāh

Muhammad (es) el enviado de Dios

príncipe de los creyentes 'Alī

Ibn Yusuf

Los soberanos almorávides incluyen sus nombres en las piezas, precedido del título de 'Amir solo o 'Amir al-muminin ("Principe de los creyentes"). En algunas piezas aparece también el nombre del príncipe heredero ${ }^{5}$, algo que ya ocurrió en determinadas emisiones califales cordobesas.

Leyenda orla anverso:

\section{و من يبتغ غير اللاسلام دينا فلن يقنل منه و هو في الاخرة من الحاسـرين فئن}

"El que desea de otra religión que no sea el Islam no le será aceptada y será en el juicio final uno de los perdedores" (Corán 3/85).

5 En nuestro caso, en la pieza $n^{\circ} 3324$.

6 Como es el caso de la pieza n 3320.
La misión profética de Mahoma característica de la orla del anverso será sustituida por la aleya 3/85 del Corán ("...el que desee otra religión que no sea el Islam no le será aceptada y será en el juicio final uno de los perdedores...."). En la península esto hacía referencia a los mozárabes, resultando, así, bastante conflictiva.

\section{Reverso}

Leyenda central reverso:

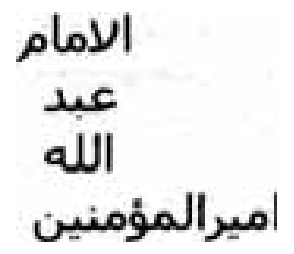

El Imām
'Abd
Allāh
Príncipe de los creyentes

Leyenda orla reverso:

\section{بسم الله ضرب هذا الدينار ببطليوس عام ثنتيعشيرة و خمسماية}

En el nombre de Dios fue acuñado este dinar en Bațalyūs el año doce y quinientos $(5 / 2 / H)$.

En el reverso podemos observar dos peculiaridades:

- La aparición de la preposición fí ( في ) en lugar de bi $(\varphi / t)$ delante de la ceca ${ }^{6}$.

- La utilización de la palabra 'ām) (عامر ) en vez de sanata ( سيـنة y que significa "año" al iniciarse la fecha de acuñación. 


\section{LAS PIEZAS}

Para abordar estas piezas hemos considerado apropiado presentarlas siguiendo un criterio cronológico, en función de su fecha de acuñación, las cuales comprenden un período que va desde el año 49| H/ I 097 d.C al 533H/

I 39 d.C y se corresponden con el mandato de tres gobernantes almorávides:

- Yūsuf ibn Tāšfin (480-500H/l 087-I l 06 d.C)

- 'Ali ibn Yūsuf (500-537H/ I | 06- | | 43 d.C)

- 'Ali ibn Yūsuf y Al-Amir Tāšrin (522-533H/ | 128- | | 39 d.C)

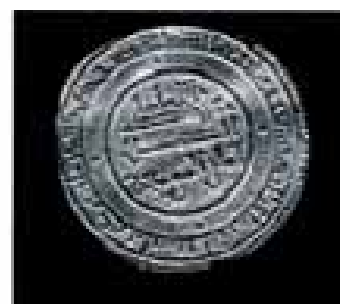

No referencia Museo: 3330

Ceca: Madīnat Išbiiliya

Fecha: 493H / 099 d.C

Gobernante: Yūsuf ibn Tāšfin (480-500H / I087-1074 d.C)

Peso: 4 gr

Módulo: $24 \mathrm{~mm}$

Ref. Vives: 1493
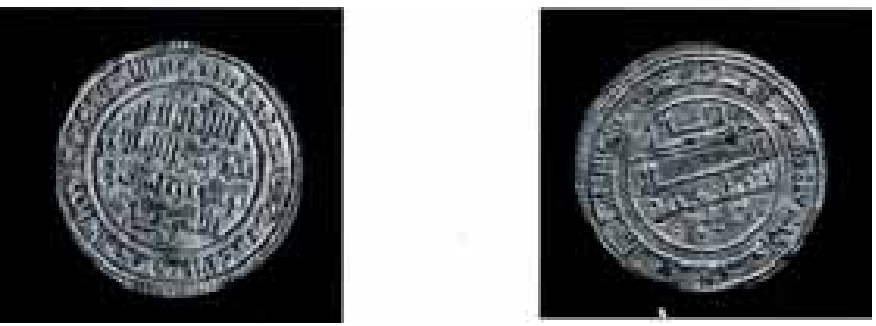

No referencia Museo: 3324

Ceca: Balinsiya (Valencia)

Fecha: 499H / II05 d.C

Gobernante: Yūsuf ibn Tāšfin (480-500H / I087-I074 d.C)

Peso: 4'06 gr

Módulo: $25 \mathrm{~mm}$

Ref. Vives: 1528

En la última línea del anverso aparece el nombre del emir heredero (al-amīr Alī) 

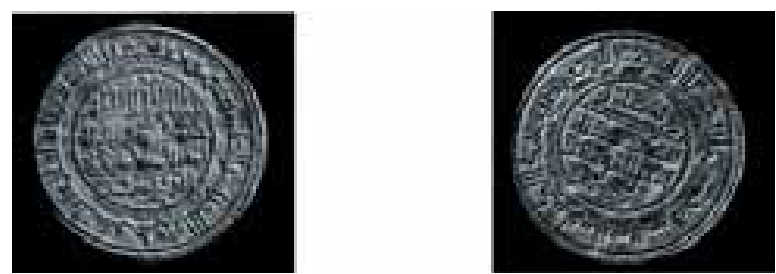

$N^{\circ}$ referencia Museo: 3334

Ceca: Balinsiya (Valencia)

Fecha: 500H / II06 d.C

Gobernante: 'Alī ibn Yūsuf (500-37H/II06-I| 43 d.C)

Peso: 4 '09 gr

Módulo: $25 \mathrm{~mm}$

Ref. Vives: 1592
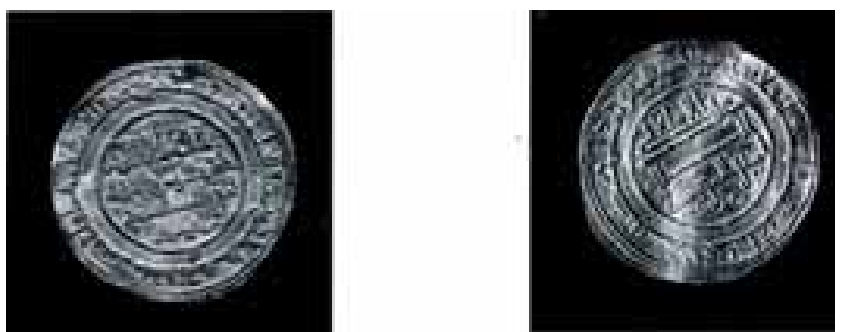

$N^{\circ}$ referencia Museo: 3318

Ceca: Mursiya (Murcia)

Fecha: 509H / III5 d.C

Gobernante: 'Alī ibn Yūsuf (500-37H/I I06-II 43 d.C)

Peso: 4'09 gr

Módulo: $25 \mathrm{~mm}$

Ref. Vives: 1631
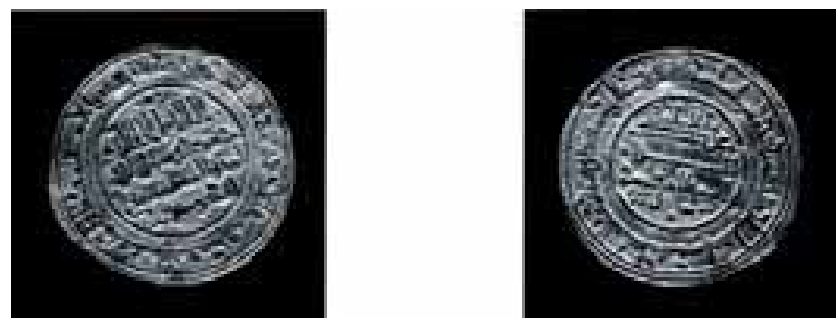

No referencia Museo: 3326

Ceca: Mursiya (Murcia)

Fecha: 5 I IH / I I 17 d.C

Gobernante: 'Alī ibn Yūsuf (500-37H / || 06-||43 d.C)

Peso: 3'9l gr

Módulo: $24 \mathrm{~mm}$

Ref. Vives: 

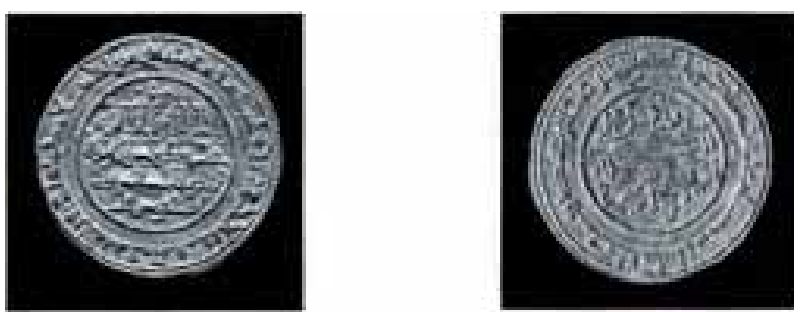

$N^{\circ}$ referencia Museo: 3319

Ceca: Mursiya (Murcia)

Fecha: 5 I2H / I I 8 d.C

Gobernante: 'Alī ibn Yūsuf (500-37H / | I06-II43 d.C)

Peso: 3'94 gr

Módulo: $25 \mathrm{~mm}$

Ref. Vives: 1633
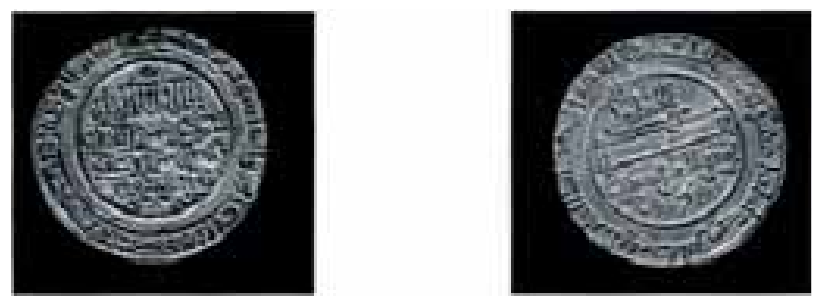

$N^{\circ}$ referencia Museo: 3321

Ceca: Batalyūs (Badajoz)

Fecha: $5 \mid 2 \mathrm{H} / \mathrm{II} 8 \mathrm{~d}$ d.C

Gobernante: 'Alī ibn Yūsuf (500-37H / II 06- II43 d.C)

Peso: 4 '03 gr

Módulo: $24 \mathrm{~mm}$

Inédita

Esta es, sin duda, la pieza más importante de este conjunto. Se trata de una ceca desconocida para ese gobernante. Se conoce la impronta de una pieza igual en la "Colección de improntas de dinares almorávides del I.V.D.J." y la fotografía de un dinar acuñado en MadTnat Batalyús en 488H/ l 095 d.0 perteneciente a una colección privada en Egipto (IBRAHIM 89).
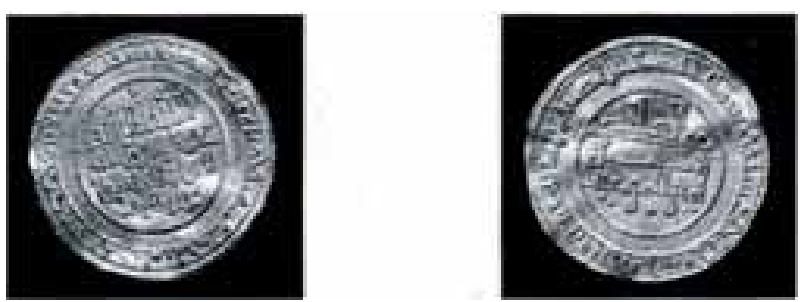

No referencia Museo: 3322

Ceca: Almiriya (Almería)

Fecha: 5 I3H / | |1 9 d.C

Gobernante: 'Alī ibn Yūsuf (500-37H / II 06- I | 43d.C)

Peso: 3 '95 gr

Módulo: $25 \mathrm{~mm}$

Ref. Vives: 1644 

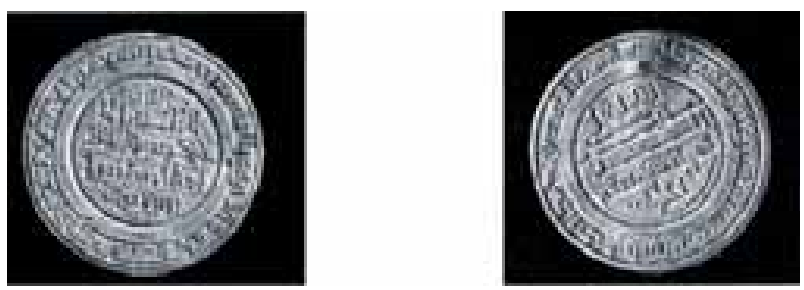

$N^{0}$ referencia Museo: 3317

Ceca: Išbîliya (Sevilla)

Fecha: $515 \mathrm{H} /$ | I2I d.C

Gobernante: 'Alī ibn Yūsuf (500-37H / II 06-II43 d.C) Peso: 4 '02 gr

Módulo: $24 \mathrm{~mm}$

Ref.Vives: 1655
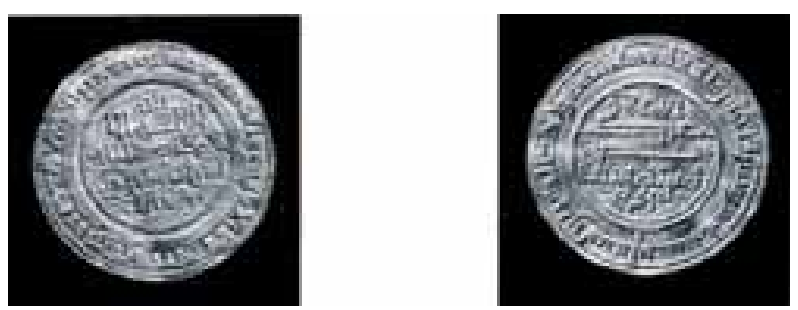

$N^{\circ}$ referencia Museo: 3323

Ceca: Išbiliya (Sevilla)

Fecha: $515 \mathrm{H} / 1|2|$ d.C

Gobernante: 'Alī ibn Yūsuf (500-37H / |l 06-||43 d.C) Peso: 3'98 gr

Módulo: $24 \mathrm{~mm}$

Ref.Vives: 1655
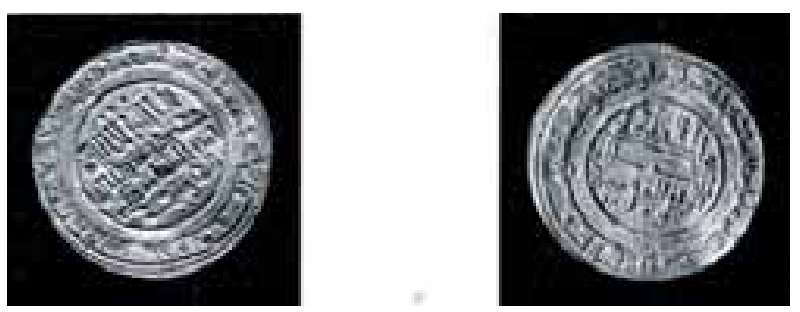

$N^{\circ}$ referencia Museo: 3316

Ceca: Almiriya (Almería)

Fecha: 5 I 5 H/ I I2I d.C

Gobernante: 'Alī ibn Yūsuf (500-37H / |l 06- |l43 d.C)

Peso: 3'95 gr

Módulo: $24 \mathrm{~mm}$

Ref.Vives: 1646 

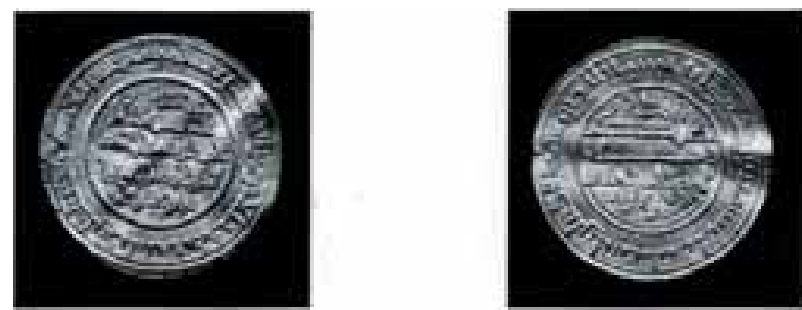

No referencia Museo: 3333

Ceca: Išbīliya (Sevilla)

Fecha: 5 I 6H / II22 d.C

Gobernante: 'Alī ibn Yūsuf (500-37H / | I 06- | I43 d.C)

Peso: 3'94 gr

Módulo: $26 \mathrm{~mm}$

Ref.Vives: 1658
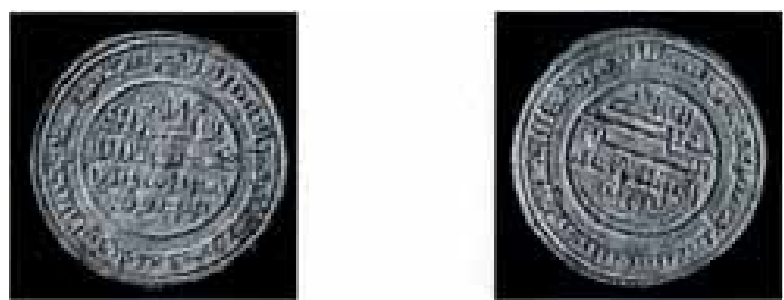

No referencia Museo: 3329

Ceca: Išbilliya (Sevilla)

Fecha: 517H / II 23 d.C

Gobernante: 'Alī ibn Yūsuf (500-37H / | | 06- | I43 d.C)

Peso: 4 '05 gr

Módulo: $25 \mathrm{~mm}$

Ref. Vives: 1659
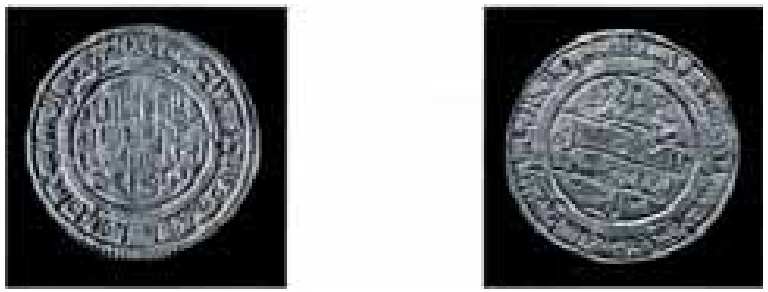

No referencia Museo: 3320

Ceca: Garnāta (Granada)

Fecha: $515 \mathrm{H} / \mathrm{I} / 2 \mathrm{ld} .0$

Gobernante: 'Alī ibn Yūsuf (500-37H/II06-I | 43d.C)

Peso: 4'02 gr

Módulo: $24 \mathrm{~mm}$

Ref. Vives: 1619

Delante de la ceca aparece la preposición fi" (ف⿴囗十) en lugar de bi (ب/t); ambas significan "en". 

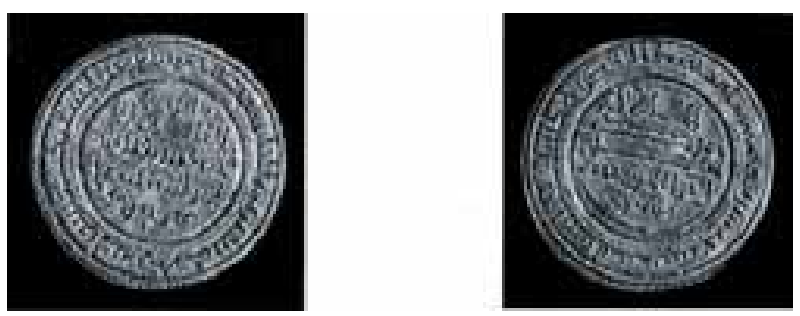

No referencia Museo: 3325/3332

Ceca: Išbîliya (Sevilla)

Fecha: 519H / II25 d.C

Gobernante: 'Alī ibn Yūsuf (500-37H / I 06- I I 43 d.C)

Peso: 4 gr / 4' 6 gr

Módulo: 25mm / 26mm

Ref. Vives: 1646
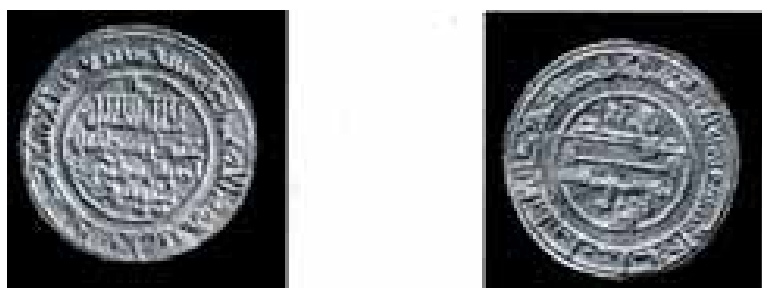

No referencia Museo: 3331

Ceca: Garnāta (Granada)

Fecha: $520 \mathrm{H} / 1126$ d.C

Gobernante: 'Alī ibn Yūsuf (500-37H / | | 06- | | 43 d.C)

Peso: 3'86 gr

Módulo: $24 \mathrm{~mm}$

Ref.Vives: 1620
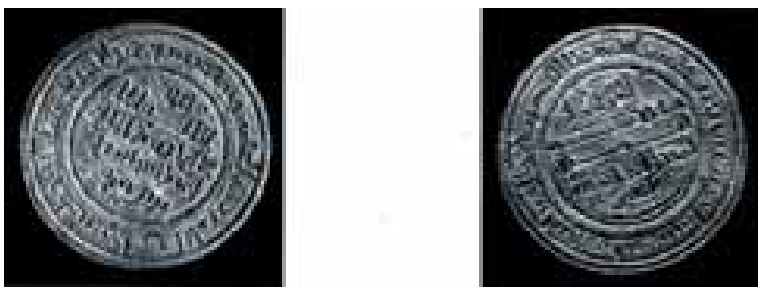

No referencia Museo: 3327

Ceca: Išbilliya (Sevilla)

Fecha: 52IH / II27 d.C

Gobernante: 'Alī ibn Yūsuf (500-37H / II 06-II43 d.C)

Peso: 4'03 gr

Módulo: $25 \mathrm{~mm}$

Ref. Vives: 1665 

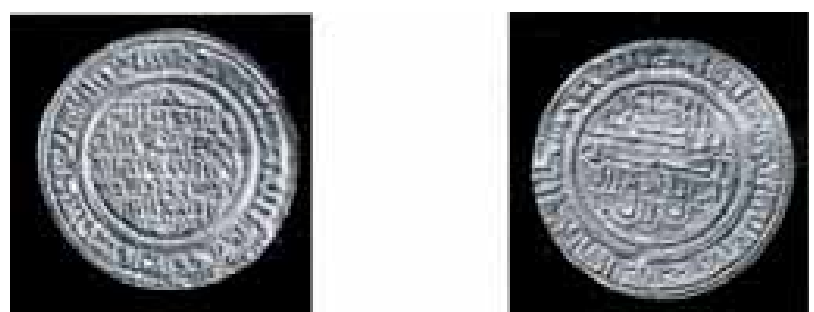

No referencia Museo: 3328

Ceca: Almiriya (Almería)

Fecha: $530 \mathrm{H} / \| 35$ d.C

Gobernante: 'Ali ibn Yūsuf y Al-Amīr Tāšfin (522-533H

|28-1139 d.C)

Peso: 3'94 gr

Módulo: $24 \mathrm{~mm}$

Ref. Vives: 1750

\section{BIBLIOGRAFÍA}

CAMPOS LÓPEZ, M.T., La Moneda Andalusí en Jaén. Una introducción. Universidad de Jaén. Museo de la Casa de la Moneda. Jaén, 2000.

CANTO GARCÍA A, TAWFIQ IBN HAFIZ I, MARTÍN ESCUDERO F. "Monedas Andalusíes" Real Academia de la Historia. Catálogo del Gabinete de Antigüedades. Madrid, 2000

DELGADO y HERNÁNDEZ, A., Estudios de Numismática Árabigo-Hispana. Considerada como un comprobante histórico de la dominación islámica de la Península. Ed. por Canto García, A. Tawfiq ibn Hāfiz Ibrāhīm. Real Academia de la Historia. Gabinete de Antigüedades. Madrid, 200 I.
IBRĀHĪM, T. "Dinares Almorávides en la Colección de Improntas del I.V.D.J. No Recogidos por Hazard" en Gaceta Numismática, nº 93 (I I-89, 3' época). Junio 1989.

MEDINA GÓMEZ, A. Monedas Hispano-Musulmanas. Instituto Provincial de Investigaciones y Estudios Toledanos. Diputación Provincial de Toledo, 1992.

PINERO JIMÉNEZ P, MARTÍNEZ ROMERO J. "Monedas Árabes Halladas en Jimena (Jaén)" en Boletín de Estudios Giennenses, año II (Mayo-Agosto) n5. Jaén 1955.

SALVATIERRA CUENCA, V. "Jaén en la Edad Media". La Historia de Jaén y su Provincia. Periódico Ideal, 1996.

VIVES y ESCUDERO, A. Monedas de las Dinastías ArabigoEspañolas, Madrid, 1893 (Reed. J. Cayón, Madrid, 1978). 